\title{
Enhanced SOX2 expression in retinoblastoma tissues and peripheral blood is associated with the clinicopathological characteristics of the disease
}

\author{
BODING TONG, JIEXI ZENG, YUJIE WU and WEI XIONG \\ Department of Ophthalmology and Eye Research Center, The Second Xiangya Hospital, \\ Central South University, Changsha, Hunan 410011, P.R. China
}

Received May 23, 2014; Accepted November 26, 2014

DOI: $10.3892 / 01.2015 .2857$

\begin{abstract}
The present study aimed to investigate the association between the expression of sex-determining region $\mathrm{Y}$ box 2 (SOX2) in retinoblastoma $(\mathrm{Rb})$ tissues and peripheral blood, and the clinicopathological characteristics of $\mathrm{Rb}$. The expression of SOX 2 in Rb tissues was detected by immunohistochemical staining and western blot analysis. SOX2 expression in the peripheral blood of children with Rb was determined using quantitative real-time polymerase chain reaction. The correlation between SOX2 expression and the clinicopathological characteristics of $\mathrm{Rb}$ was analyzed using $\chi^{2}$ tests. The positive rate of SOX2 in $\mathrm{Rb}$ tissues was $82.2 \%$, while the expression of SOX2 in the control group tissues was negative. Western blot analysis detected a higher expression of SOX 2 in the $\mathrm{Rb}$ tissues than in the control group tissues. Poorly differentiated $\mathrm{Rb}$ tissues exhibited significantly higher levels of SOX2 expression compared with the well-differentiated Rb tissues. SOX2 expression was higher in the peripheral blood of children with $\mathrm{Rb}$ than in individuals from the control group. The level of SOX2 expression in the peripheral blood of the poorly differentiated group was higher than that of the well-differentiated group. Enhanced SOX2 expression in Rb tissues and peripheral blood was closely associated with the clinicopathological characteristics of Rb. Therefore, SOX2 may be a novel target biomarker for the clinical diagnosis and treatment of $\mathrm{Rb}$.
\end{abstract}

\section{Introduction}

Retinoblastoma $(\mathrm{Rb})$ is a common primary intraocular malignancy that affects children. Rb can cause serious damage to the eyes and vision, or may lead to mortality as a result

Correspondence to: Dr Wei Xiong, Department of Ophthalmology and Eye Research Center, The Second Xiangya Hospital, Central South University, 139 Renmin Road, Changsha, Hunan 410011, P.R. China

E-mail: xiongw777@163.com

Key words: retinoblastoma, SOX2, immunohistochemistry staining of intracranial and systemic metastases at a later stage (1). Previous studies have identified that multiple genes have an important role in the incidence and development of $\mathrm{Rb}(2,3)$. $\mathrm{The} \mathrm{Rb}$ gene demonstrates good prospects for the early diagnosis, treatment, pathological classification and prognosis of $\mathrm{Rb}$ (4). Therefore, the search for novel genes, which are associated with $\mathrm{Rb}$, has become a topic of interest in recent years $(5,6)$. The sex-determining region $\mathrm{Y}$ box 2 (SOX2) is an embryonic stem cell gene, which has a key role in embryonic tissue development (7). An abnormal expression of SOX2 has been identified in lung, stomach, liver and breast cancers, and in other tumors, which suggests that SOX2 may function in tumor development, invasion and metastasis (8-10). At present, the role of SOX 2 expression in $\mathrm{Rb}$, and its underlying mechanisms, are unclear. The present study aimed to analyze the gene and protein expression of SOX2 in the Rb tissues of 45 children, and in the peripheral blood of 15 children with $\mathrm{Rb}$, and also identify any association between SOX2 expression and the clinicopathological features of the disease.

\section{Materials and methods}

Tissue samples. Tissue samples were collected from 45 children with $\mathrm{Rb}$ ( 28 male and 17 female; aged between 1 month and 108 months, with a mean age of 32 months) who had undergone treatment at the The Second Xiangya Hospital (Changsha, China), between December 2010 and December 2013. Of these patients, 32 had unilateral $\mathrm{Rb}$ and 13 had bilateral $\mathrm{Rb}$. The children were grouped according to the International Intraocular Retinoblastoma Classification (10) as follows: i) N0 stage, no invasion of the optic nerve by the tumors; ii) N1 stage, tumor invasion of the optic nerve head that did not exceed the sieve; iii) N2 stage, tumor penetrated through the sieve, but no tumor cell invasion of the optic nerve stump; and iv) N3 stage, tumor cells at optic nerve stump. The tissues were divided into a well-differentiated group and a poorly differentiated group, depending upon whether the tumor cells were arranged into a Flexner-Winterstein rosette. In the present study, six cases were at N0 stage, five cases were at N1 stage, 16 cases were at $\mathrm{N} 2$ stage and 18 cases were at N3 stage. In total, 31 samples belonged to the well-differentiated group and 14 samples belonged to poorly differentiated group. In addition, 15 pieces 
of normal retinal tissue, which had surrounded the $\mathrm{Rb}$ tumors, were collected to represent the control group. Written informed consents were obtained from the family members of the patients, and the study was approved by the Ethics Review Board of Central South University, Changsha, China.

Reagents. The serum RNA extraction reagent TRIzol LS and the total RNA extraction reagent TRIzol were purchased from Invitrogen (Carlsbad, CA, USA). The rabbit anti-human SOX2 polyclonal antibodies were purchased from Santa Cruz Biotechnology, Inc. (Santa Cruz, CA, USA). The reverse transcription system was purchased from Takara Bio, Inc. (Shiga, Japan). The streptavidin-peroxidase immunohistochemical kits were purchased from Beijing Zhongshan Co. (Beijing, China). The quantitative reverse transcription polymerase chain reaction (qRT-PCR) kit for mRNA was purchased from Kapa Biosystems, Inc. (Wilmington, MA, USA).

Immunohistochemistry. The streptavidin-peroxidase two-step method was used for the immunohistochemical staining. A portion of the tumor tissues was fixed in $10 \%$ formaldehyde, embedded in paraffin, sliced and then soaked in xylene diluent for dewaxing. Subsequent to blocking non-specific binding with horse serum, the polyclonal rabbit anti-human SOX2 antibody (dilution, 1:200; cat. no. ab171380) was added, followed by a 30 -min incubation with biotin-labeled polyclonal goat anti-mouse IgG (dilution, 1:3,000; cat. no ab6789) and polyclonal goat anti-rabit IgG (dilution, 1:2,000; cat. no. ab6721) secondary antibodies (Abcam, Cambridge, MA, USA) at $37^{\circ} \mathrm{C}$. After washing three times with phosphate-buffered saline, the streptavidin-peroxidase complexes were added to the samples for $30 \mathrm{~min}$. Next, diaminobenzidine staining was performed. After washing with phosphate-buffered saline three times, the mixture was mildly stained with hematoxylin and eosin, differentiated with hydrochloric acid, washed with tap water, dehydrated with graded alcohol and then mounted with neutral gum.

Microscopy. Each slice was observed under an Olympus BX53 optical microscope (Olympus Corporation, Tokyo, Japan) (magnification, x400). Brown or sepia granular staining of the cytoplasm or cellular membrane indicated positive cells. In total, five high-power fields were randomly selected for the tumor cell count. The percentage of positive cells was represented by the ratio of stained tumor cells to the total number of tumor cells in the field. The average percentage of positive cells was calculated from the five fields. The final score was calculated as follows: Final score $=$ degree of staining x percentage of positive cells in each field. The final scores were presented as follows: $0-1$, negative; $2-3$, weak positive; $4-6$, positive; $>6$, strong positive.

Western blotting. In order to extract the total proteins, $\mathrm{Rb}$ tissues were lysed with radio-immunoprecipitation assay protein (Beyotime Institute of Biotechnology, Haimen, China). Next, SDS-PAGE was performed for $2 \mathrm{~h}$. The proteins were then transferred to a polyvinylidene difluoride membrane, and blocked with $5 \%$ skimmed milk for $1 \mathrm{~h}$ at room temperature. Next, primary antibodies against the target protein, SOX2 (dilution, 1:1,000), and the internal reference protein,
Table I. Primers for quantitative reverse transcription polymerase chain reaction.

Primer Sequence (5' to $3^{\prime}$ )

SOX2, forward

GAGAGTGTTTGCAAAAGGGGG

SOX2, reverse GCTTCTCCGTCTCCGACAAA

GAPDH, forward CTCTGCTCCTCCTGTTCGAC

GAPDH, reverse GCGCCCAATACGACCAAATC

SOX2, sex-determining region $\mathrm{Y}$ box 2 .

GAPDH (polyclonal rabbit anti-human antibody; dilution, 1:3,000; cat. no. ab9485; Abcam), were added proportionally. The horseradish peroxidase-labeled secondary antibodies for SOX2 (goat anti-mouse; dilution, 1:3,000) and GAPDH (goat anti-rabbit; dilution, 1:2,000) were then added, followed by incubation at room temperature for $1 \mathrm{~h}$. The membrane was then washed with phosphate-buffered saline with Tween 20 three times for 15 min each time, and developed with electrochemiluminescence liquid.

$R T$-qPCR. Overall, $6 \mu 1$ total RNA was used for the reverse transcription reaction, and the expression of SOX2 in the peripheral blood was determined by RT-qPCR. For reverse transcription, the reaction conditions were as follows: $42^{\circ} \mathrm{C}$ for $45 \mathrm{~min}$. The reaction system consisted of $10 \mu \mathrm{l}$ qRT-PCR-Mix, $0.5 \mu \mathrm{l}$ upstream primer, $0.5 \mu \mathrm{l}$ downstream primer, $1 \mu \mathrm{l}$

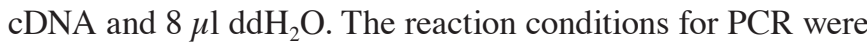
as follows: pre-denaturation at $94^{\circ} \mathrm{C}$ for $5 \mathrm{~min}$, followed by 40 cycles of $94^{\circ} \mathrm{C}$ for $30 \mathrm{sec}, 60^{\circ} \mathrm{C}$ for $30 \mathrm{sec}$ and $72^{\circ} \mathrm{C}$ for $20 \mathrm{sec}$, and a final extension step at $72^{\circ} \mathrm{C}$ for $5 \mathrm{~min}$. Three parallel wells were set up for each sample. The internal reference gene was GAPDH, and the associated primers are listed in Table I. The $2^{-\triangle \Delta C T}$ method was used to calculate the relative expression level of SOX2.

Statistical analysis. Data was analyzed using SPSS version 16.0 statistical software (SPSS, Inc., Chicago, IL, USA). The data are expressed as the mean \pm standard deviation. Group t-test was used for the comparison of SOX 2 expression between groups in the peripheral blood of Rb children. The $\chi^{2}$ test was used to analyze the association of SOX2 protein expression with the clinicopathological features of $\mathrm{Rb}$. A value of $\mathrm{P}<0.05$ was used to indicate a statistically significant difference.

\section{Results}

SOX2 expression in Rb tissues is dependent upon the degree of $R b$ differentiation and optic nerve invasion. In order to analyze the expression of SOX2 in Rb tissues, immunohistochemical staining was performed. The results revealed that SOX2 was expressed either in the cytoplasm or the cell membrane of $\mathrm{Rb}$ cells, or in both (Fig. 1). SOX2 expression in Rb tissues was positive, and included 10 weak positive cases $(22.2 \%)$, 14 positive cases $(31.1 \%)$ and 21 strong positive cases $(46.7 \%)$. By contrast, SOX2 expression in the control group was negative. The comparison of SOX2 expression between groups 
Table II. Correlation of sex-determining region Y box 2 (SOX2) expression and clinicopathological features of retinoblastoma.

\begin{tabular}{|c|c|c|c|c|}
\hline Variables & $\mathrm{n}$ & Percentage of positive SOX2 expression & $\chi^{2}$ & P-value \\
\hline \multicolumn{5}{|l|}{ Gender } \\
\hline Male & 28 & 100 & & \\
\hline Female & 17 & 100 & & \\
\hline Optic nerve invasion & & & 29.152 & 0.000 \\
\hline N0-1 & 11 & $0^{\mathrm{a}}$ & & \\
\hline $\mathrm{N} 2$ & 16 & $25^{\mathrm{a}}$ & & \\
\hline N3 & 18 & $94^{\mathrm{a}}$ & & \\
\hline Differentiation & & & 23.226 & 0.000 \\
\hline Well & 31 & $23^{\mathrm{a}}$ & & \\
\hline Poor & 14 & $100^{\mathrm{a}}$ & & \\
\hline
\end{tabular}

aPercentage of strong positive SOX2 expression.

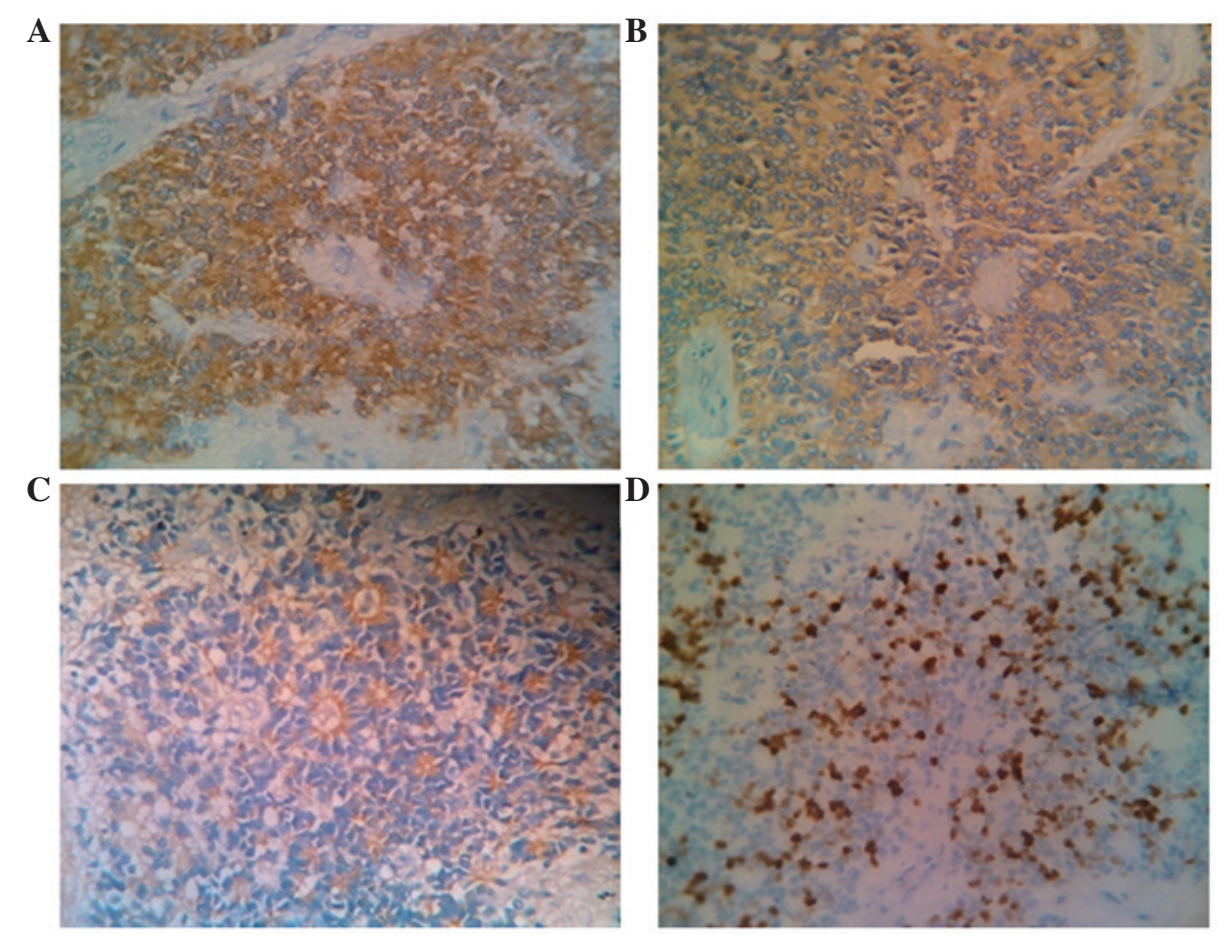

Figure 1. Immunohistochemical analysis revealing the expression of sex-determining region Y box 2 (SOX2) protein in retinoblastoma tissues (magnification, x10). (A) Strong positive expression of SOX2. (B) Positive expression of SOX2. (C) Weak positive expression of SOX2 in the cytoplasm. (D) Positive expression of SOX2 in the nucleus.

of varying $\mathrm{Rb}$ differentiation revealed that the expression was strong positive in the 14 cases of poorly differentiated $\mathrm{Rb}$. However, in the well-differentiated group, there were seven cases of strong positive expression, 14 cases of positive expression, and 10 cases of weak positive expression. The comparison of SOX2 expression between groups of different $\mathrm{Rb}$ stages revealed that there were nine cases of weak positive SOX2 expression, and two cases of positive SOX2 expression in the N0-N1 stage tissues; four cases of strong positive SOX2 expression, 11 cases of positive SOX 2 expression and one case of weak positive SOX2 expression in the N2 stage tissues; and 17 cases of strong positive SOX2 expression and one case of positive SOX2 expression in the N3 stage tissues.
The comparison between genders revealed that there were no statistically significant differences between the SOX 2 positive expression rates $(\mathrm{P}<0.05)$ (Table II). These data suggest that SOX 2 expression in $\mathrm{Rb}$ tissues is dependent upon the degree of $\mathrm{Rb}$ differentiation and optic nerve invasion.

SOX2 protein expression is correlated with the development and invasion of $R b$. Western blot analysis was performed in order to measure the expression of SOX2 protein within the $\mathrm{Rb}$ tissues. The results revealed that $\mathrm{SOX} 2$ protein expression was significantly higher in the $\mathrm{Rb}$ tissues than in the control group tissues $(\mathrm{P}<0.05)$ (Fig. $2 \mathrm{~A})$. In addition, SOX2 protein expression was significantly higher in the poorly differentiated 
A

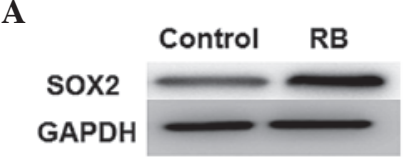

B

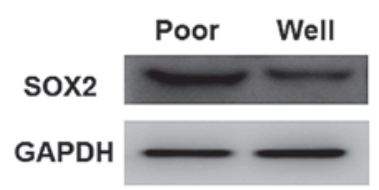

C

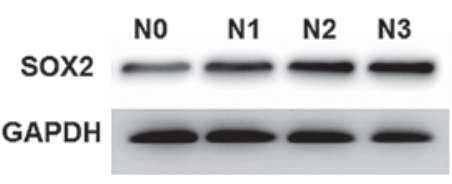

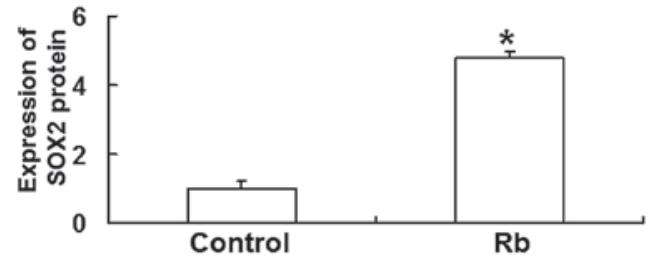
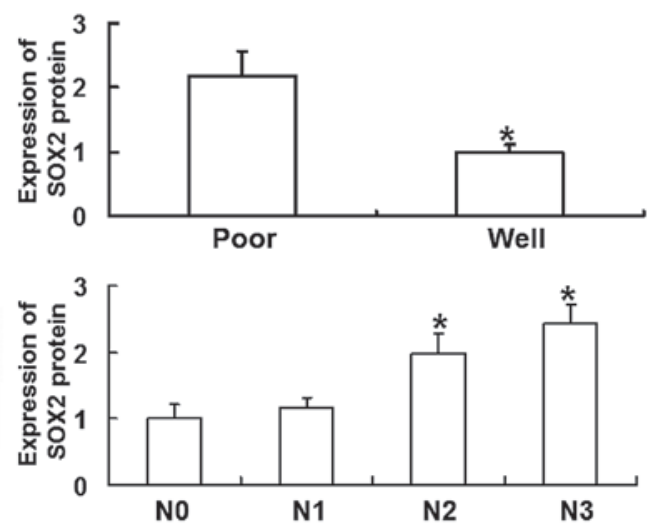

Figure 2. Sex-determining region Y box 2 (SOX2) protein expression in retinoblastoma ( $\mathrm{Rb}$ ) tissues, as detected by western blot analysis. The quantification of western blots were plotted into histograms. (A) SOX2 protein expression in Rb and control tissues. " $\mathrm{P}<0.05$, compared with the control group. (B) SOX2 protein expression in the poorly and well-differentiated groups. " $\mathrm{P}<0.05$, compared with the poorly differentiated group. (C) SOX 2 protein expression in $\mathrm{Rb}$ tissues at stages N0, N1, N2 and N3. "P<0.05, compared with the N0 group. All data are presented as the mean \pm standard error of the mean.

A

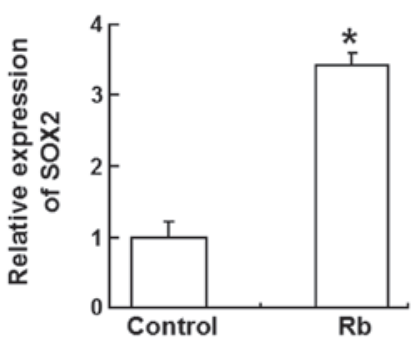

B

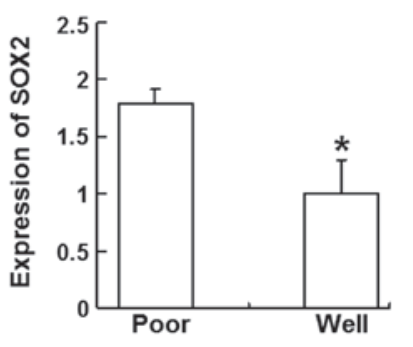

Figure 3. Sex-determining region Y box 2 (SOX2) gene expression in the peripheral blood of children with retinoblastoma $(\mathrm{Rb})$. The quantification of the quantitative reverse transcription polymerase chain reactions were plotted into histograms. (A) Relative expression of SOX 2 mRNA in the peripheral blood of control individuals and $\mathrm{Rb}$ patients. ${ }^{*} \mathrm{P}<0.05$, compared with the control group (B) Expression of SOX2 mRNA in the peripheral blood of the poorly and well-differentiated groups. ${ }^{*} \mathrm{P}<0.05$, compared with the poorly differentiated group. All data are presented as the mean \pm standard error of the mean.

group than in the well-differentiated group $(\mathrm{P}<0.05)$ (Fig. 2B). Furthermore, SOX2 protein expression increased as the optic nerve invasion progressed from stage N0 to N3, with the expression significantly higher at the N2 and N3 stages than the N0 stage $(\mathrm{P}<0.05)$ (Fig. 2C). These results suggest that SOX2 protein expression is correlated with the development and invasion of $\mathrm{Rb}$.

SOX2 gene is highly expressed in the peripheral blood of $R b$ children, with expression in the poorly differentiated group higher than that in well-differentiated group. In order to determine the SOX2 gene expression in the peripheral blood of children with Rb, RT-qPCR was performed. In total, SOX2 gene expression was detected in $15 \mathrm{Rb}$ children, including five poorly differentiated cases and eight well-differentiated cases. The quantitative results demonstrated that SOX2 gene expression

was significantly higher in the peripheral blood of $\mathrm{Rb}$ children than in individuals from the control group $(\mathrm{P}<0.05)$ (Fig. 3A). In addition, SOX 2 gene expression in the poorly differentiated group was higher than that observed in the well-differentiated group $(\mathrm{P}<0.05)$ (Fig. 3B). These data indicate that the SOX2 gene was highly expressed in the peripheral blood of children with $\mathrm{Rb}$, with expression higher in the poorly differentiated group compared with the well-differentiated group.

\section{Discussion}

In recent years, genes have been discovered that are closely associated with the development of $\mathrm{Rb}(12,13)$. Previous studies have demonstrated that $\mathrm{Rb}$ gene mutations and deletions occur in the majority children with $\mathrm{Rb}(14,15)$. Furthermore, in vitro experiments have indicated that the $\mathrm{Rb}$ gene has important roles in the incidence, metastasis, apoptosis and other aspects of $\mathrm{Rb}$. Vascular endothelial growth factor has been demonstrated to promote $\mathrm{Rb}$ tumor angiogenesis (16). The melanoma differentiation associated gene-7 has been shown to selectively induce the apoptosis and inhibit the growth of Rb tumor cells (17). The identification of these novel biomarkers has led studies to investigate the molecular mechanism of $\mathrm{Rb}$, and has provided an alternative approach for clinical diagnosis and treatment.

The SOX2 gene, a member of the SOX gene family, is an important transcription factor that regulates embryotic development and cell differentiation, and which functions in the embryotic development of the brain, nerves, lens and other tissue structures. The abnormal expression of SOX2 can often lead to cellular and tissue differentiation in developmental disorders $(18,19)$. Therefore, the function of the SOX2 gene in abnormally differentiated tumor tissues has become of particular interest. Previous studies have demonstrated that the expression of SOX2 is increased in lung, liver and stomach 
cancers, and in other tumor tissues, and that it is positively correlated with the clinicopathological stages and degrees of differentiation of $\mathrm{Rb}(20,21)$. In vitro experiments have confirmed that SOX2 functions in the malignant biological behaviors of a variety of tumor cells $(22,23)$. In the present study, immunohistochemistry, western blotting and RT-qPCR were performed in order to detect the expression of SOX2 in $\mathrm{Rb}$ tissues and peripheral blood. In addition, the correlations between SOX2 expression and the degree of differentiation and clinical stage of $\mathrm{Rb}$ were preliminarily analyzed using the clinicopathological data. It has been reported that SOX-2 expression is elevated in $\mathrm{Rb}$ tissues (14,24-27). For example, Wadhwa et al (24) observed that SOX2 is expressed in the inner retina and the ganglion cells of human RB tumors. Zhang et al (25) identified Sox 2 as one of the upregulated genes in $\mathrm{Rb}$ tissues using a chromatin immunoprecipitation-on-chip analysis. Our results were consistent with these previous reports.

The results of the present study indicate that the SOX2 protein, as a key transcription factor in the embryotic development and tissue cell differentiation, has an important role in the incidence and development of Rb. Due to the diversity of the downstream target genes that can be regulated by SOX2, the specific molecular mechanism of SOX2 requires further study. The peripheral blood results suggested that SOX2 gene expression may be clinically useful for the early diagnosis and treatment of children with $\mathrm{Rb}$.

To summarize, the SOX2 gene was highly expressed in $\mathrm{Rb}$ tissues and in the peripheral blood. Furthermore, its expression increased with the progression of clinical stage and with the lowering of the degree of differentiation. The present study indicates that SOX2 has an important role in the incidence and development of $\mathrm{Rb}$. However, the downstream molecular mechanism requires further study in order to provide a theoretical basis for the clinical diagnosis and treatment of $\mathrm{Rb}$.

\section{Acknowledgements}

The present study was supported by a grant from the National Nature Science Foundation of China (no. 81371013).

\section{References}

1. Villegas VM, Hess DJ, Wildner A, et al: Retinoblastoma. Curr Opin Ophthalmol 24: 581-588, 2013.

2. Jehanne M, Brisse H, Gauthier-Villars M, et al: Retinoblastoma: recent advances. Bull Cancer 101: 380-387, 2014 (In French).

3. Aerts I, Lumbroso-Le Rouic L, Gauthier-Villars M, et al: Retinoblastoma. Orphanet J Rare Dis 1: 31-41, 2006.

4. Temming P, Eggert A, Bornfeld N, et al: Diagnosis and treatment of retinoblastoma: current strategies for effective tumour contro and preservation of vision. Klin Monbl Augenheilkd 230: 232-242, 2013 (In German).

5. Hilgendorf KI, Leshchiner ES, Nedelcu S, et al: The retinoblastoma protein induces apoptosis directly at the mitochondria. Genes Dev 27: 1003-1015, 2013.
6. Lai D, Visser-Grieve S and Yang X: Tumour suppressor genes in chemotherapeutic drug response. Biosci Rep 32: 361-374, 2012.

7. Sarkar A and Hochedlinger K: The sox family of transcription factors: versatile regulators of stem and progenitor cell fate. Cell Stem Cell 12: 15-30, 2013.

8. Liu K, Lin B, Zhao M, et al: The multiple roles for Sox 2 in stem cell maintenance and tumorigenesis. Cell Signal 25: 1264-1271, 2013.

9. Teicher BA: Targets in small cell lung cancer. Biochem Pharmacol 87: 211-219, 2014.

10. Lipka AF, Verschuuren JJ and Titulaer MJ: SOX1 antibodies in Lambert-Eaton myasthenic syndrome and screening for small cell lung carcinoma. Ann N Y Acad Sci 1275: 70-77, 2012.

11. Linn Murphree A: Intraocular retinoblastoma: the case for a new group classification. Ophthalmol Clin North Am 18: 41-53, 2005.

12. Cecchini MJ, Thwaites M, Talluri S, et al: A retinoblastoma allele that is mutated at its common E2F interaction site inhibits cell proliferation in gene targeted mice. Mol Cell Biol 34: 2029-2045, 2014.

13. Liu R, Zhang XH, Zhang K, et al: 5-Aza-2'-deoxycytidine inhibits retinoblastoma cell by reactivating epigenetically silenced RASSF1A gene. Int J Ophthalmol 7: 51-56, 2014.

14. Thériault BL, Dimaras H, Gallie BL and Corson TW: The genomic landscape of retinoblastoma: a review. Clin Experiment Ophthalmol 42: 33-52, 2014.

15. Madhavan J, Ganesh A and Kumaramanickavel G: Retinoblastoma: from disease to discovery. Ophthalmic Res 40: 221-226, 2008.

16. Xin GH, Zhao XH, Liu D, et al: Effect of VEGF-targeted antisense gene therapy on retinoblastoma cell line SO-RB50 in vitro and in vivo. Int J Ophthalmol 5: 440-447, 2012.

17. Mhashilkar AM, Schrock RD, Hindi M, et al: Melanoma differentiation associated gene-7 (mda-7): a novel anti-tumor gene for cancer gene therapy. Mol Med 7: 271-282, 2001.

18. Popovic J, Stanisavljevic D, Schwirtlich M, et al: Expression Analysis of SOX14 during retinoic acid induced neural differentiation of embryonal carcinoma cells and assessment of the effect of its ectopic expression on SOXB members in HeLa Cells. PLoS One 9: e91852, 2014

19. Lin IY, Chiu FL, Yeang CH, et al: Suppression of the SOX2 neural effector gene by PRDM1 promotes human germ cell fate in embryonic stem cells. Stem Cell Reports 2: 189-204, 2014.

20. Weina K and Utikal J: SOX2 and cancer: current research and its implications in the clinic. Clin Transl Med 3: 19, 2014.

21. Jia X, Li X, Xu Y, et al: SOX2 promotes tumorigenesis and increases the anti-apoptotic property of human prostate cancer cell. J Mol Cell Biol 3: 230-238, 2011.

22. Fujii T, Shimada K, Tatsumi Y, et al: Syndecan-1 responsive microRNA-126 and 149 regulate cell proliferation in prostate cancer. Biochem Biophys Res Commun: Nov 22, 2014 (Epub ahead of print).

23. Chou MY, Hu FW, Yu CH and Yu CC: Sox 2 expression involvement in the oncogenicity and radiochemoresistance of oral cancer stem cells. Oral Oncol 51: 31-39, 2015.

24. Wadhwa L, Bond WS, Perlaky L, et al: Embryonic retinal tumors in SV40 T-Ag transgenic mice contain CD133+ tumor-initiating cells. Invest Ophthalmol Vis Sci 53: 3454-3462, 2012.

25. Zhang J, Benavente CA, McEvoy J, et al: A novel retinoblastoma therapy from genomic and epigenetic analyses. Nature 481: 329-334, 2012.

26. Seigel GM, Campbell LM, Narayan M and Gonzalez-Fernandez F: Cancer stem cell characteristics in retinoblastoma. Mol Vis 11: 729-737, 2005.

27. Seigel GM, Hackam AS, Ganguly A, et al: Human embryonic and neuronal stem cell markers in retinoblastoma. Mol Vis 13: 823-832, 2007. 